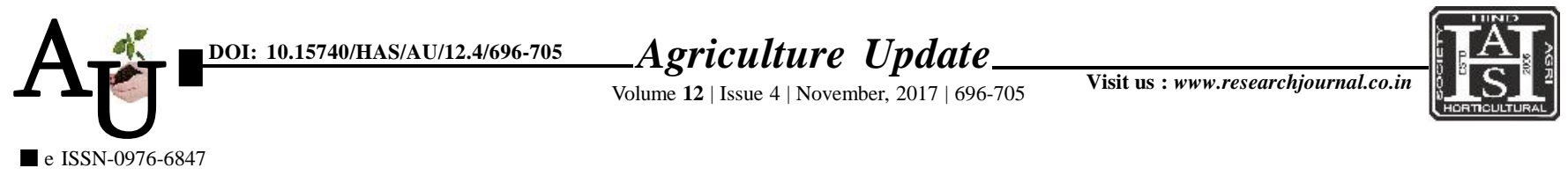

\title{
Research article: Cyber extension for better nutritional security: Some developments and perspectives
}

\author{
R. NAGARJUNA KUMAR, C.A. RAMA RAO, B.M.K. RAJU, K. SREEDEVI \\ SHANKAR, G. NIRMALA, K. RAVI SHANKAR, K. SAMMI REDDY AND B. \\ SAILAJA
}

Article Chronicle: Received :

11.09.2017;

Revised :

05.10.2017;

Accepted :

21.10.2017

KeY WoRDS:

Nutrition security,

Mobile phones, GPS,

Knowledge

Author for correspondence :

R. NAGARJUNA KUMAR

Central Research

Institute for Dryland

Agriculture (CRIDA),

Santosh Nagar,

HYDERABAD

(TELANGANA), INDIA

Email:rnagarjunakumar@

yahoo.com

See end of the article for

authors' affiliations
SUMMARY : India registered remarkable economic growth during the first decade of this millennium. Ironically, during this period, a vast section of population remained undernourished. The annual economic losses associated with malnutrition have been estimated at 3 per cent of India's gross domestic product (GDP). Experience shown that increasing food production alone cannot address the issue of malnutrition, unless there is a nutrition focus and the poorest have access to a source of diversified and nutritious foods. Knowledge and information are important factors to ensure food and nutrition security. The problem of malnutrition can be better addressed through a innovative ICT led extension systems. Rapid advances in data acquisition and management, modeling, computation power, and information technology provide the opportunity to harness this knowledge in new and powerful ways to achieve more productive and sustainable agricultural systems. Examples of this technology include mobile phones, social media, tablets, internet, email, global positioning systems (GPS) etc. In this paper we employ the use cases and our collective experiences with agricultural systems and Information and communication technology (ICT) to describe about data and knowledge products need to improve food security and better nutrition.

How to cite this article : Nagarjuna Kumar, R., Rama Rao, C.A., Raju, B.M.K., Sreedevi Shankar, K., Nirmala, G., Ravi Shankar, K., Sammi Reddy, K. and Sailaja, B. (2017). Cyber extension for better nutritional security: Some developments and perspectives. Agric. Update, 12(4): 696-705; DOI : 10.15740/HAS/AU/12.4/696-705. 